Article

\title{
A Comprehensive Physical Profile for Aqueous Dispersions of Carbon Derivatives as Solar Working Fluids
}

\author{
Elisa Sani ${ }^{1}$, Javier P. Vallejo ${ }^{2, *(D)}$, Luca Mercatelli ${ }^{1}$, Maria Raffaella Martina ${ }^{1}$, \\ Daniele Di Rosa ${ }^{1,3}$, Aldo Dell'Oro ${ }^{4}$ and Luis Lugo ${ }^{2}(\mathbb{C}$ \\ 1 CNR-INO National Institute of Optics, Largo E. Fermi, 6, I-50125 Firenze, Italy; elisa.sani@ino.cnr.it (E.S.); \\ luca.mercatelli@ino.cnr.it (L.M.); mariaraffaella.martina@ino.cnr.it (M.R.M.); daniele.dirosa@ino.it (D.D.R.) \\ 2 Departamento de Física Aplicada, Facultade de Ciencias, Universidade de Vigo, E-36310 Vigo, Spain; \\ luis.lugo@uvigo.es \\ 3 Department of Energy, Systems, Territory and Constructions, University of Pisa, Engineering (D.E.S.T.eC.), \\ Largo L. Lazzarino, I-56122 Pisa, Italy \\ 4 INAF, Osservatorio Astrofisico di Arcetri, Largo E. Fermi 5, I-50125 Firenze, Italy; aldo.delloro@inaf.it \\ * Correspondence: jvallejo@uvigo.es; Tel.: +34-986-813-771
}

Received: 10 December 2019; Accepted: 8 January 2020; Published: 10 January 2020

\begin{abstract}
The application of nanofluids in direct solar absorption, heat transfer or direct solar steam generation entails carrying out a comprehensive study taking into account several physical quantities. Long-term stability, rheological, thermophysical and optical properties of dispersions must be known to assess their potential for envisaged applications. Two low-concentration nanofluids, 0.005 and $0.05 \mathrm{wt} \%$, of sulfonic acid-functionalized and polycarboxylate chemically modified graphene nanoplatelets in water were considered in this work. Elemental analyses of the nanopowders and $\mathrm{pH}$ evaluations of the colloids were carried out. The rheological behaviour of dispersions at different temperatures was studied by rotational rheometry. Thermal conductivities were measured by the transient hot wire method and densities by the oscillating U-tube technique. Additionally, a brief report of the optical properties was included to provide a comprehensive physical analysis.
\end{abstract}

Keywords: water nanofluid; graphene; solar energy; heat transfer; viscosity

\section{Introduction}

Choi and Eastman [1] first proposed that nanometer-sized solid particles could be suspended in conventional heat-transfer fluids to enhance the thermal conductivity. Thereafter, many scholars from different research areas recognized the potential of nanofluids, which could provide benefits not only for heat transfer [2], but also in other fields (e.g., biology, medicine, optics, electronics and energy).

Nanofluids have renewed the research about solar energy applications [3,4], especially in concentrated solar power (CSP) by direct absorption solar collectors (DASCs). The working principle of DASCs, which were firstly proposed by Minardi and Chuang [5], is the same as conventional parabolic trough collectors (PTCs). These systems converge the sunlight irradiance towards a central absorber tube, where a working fluid is heated and then used for power or heat generation. Conventional PTCs feature a dark coating on the absorber tube, which allows it to capture the light and carry the energy to the inner fluid, which is usually transparent. On the other side, DASCs are equipped with a transparent absorber tube, where a dark fluid flows. This provides a twofold advantage, because the conductive thermal resistance of the coating is removed, and the emittance losses towards the external environment are decreased. Indeed, whereas the external coating of the absorber tube represents its hottest region in the case of conventional PTCs, the temperature distribution of DASCs is reversed, so that the boundary 
of the absorber are colder. In the mid-1970s, when DASC systems were first tested, a black fluid based on a dispersion of micro-sized carbonaceous particles with organic stabilizers, called Indian Ink, was typically used. However, it was very unstable at high temperatures, resulting in sedimentation and serious clogging issues within a short operating time [6]. Nanofluids, properly produced and employed, could overcome these drawbacks. These dispersions of nano-sized solid particles in a base fluid represent a stable, high conductive and adaptable working fluid for DASC systems.

Direct solar steam generation is another interesting field of application, which could benefit from the use of nanofluids. Steam has a wide spectrum of uses, like electricity generation, energy storage, biomass processing or water desalination and purification. To reduce the environmental impact linked to the steam production, different solutions based on renewable energies have been proposed through the years, and solar energy is not an exception. Solar towers or parabolic trough collectors are the architectures traditionally used for solar steam generation $[7,8]$. The concept underlying these systems, concentrating the light to heat a bulk fluid over its boiling temperature, is not so efficient because the high temperature levels involve heavy losses due to heat convection and re-irradiation from the hot container. Instead, nanofluids could provide a new way to achieve more favorable steam generation. Many studies report the formation of vapor bubbles inside nanofluids, despite the average temperature of the bulk fluid being below the boiling point [9-12]. Although the mechanisms governing this phenomenon are still not fully understood, the solid nanoparticles could act as nucleating centers triggering complex heat-transfer phenomena at the solid-liquid interface and eventually leading to the growth of vapor bubbles [13]. This can suggest that vapor could be generated locally, without the need for heating the whole bulk fluid.

Remarkable efforts have been made to understand which nanofluid could better fit the requirements of the desired application $[6,10,12,14-23]$. Concerning DASC systems, it is a hard task to find a nanofluid that provides suitable chemical, thermophysical, fluid-dynamics and optical properties at the same time, as it must work both as a heat carrier and as a light absorber. However, some types of nanoparticles have become promising, such as the family of carbon-based nanostructures. Graphite [10,14], single and multi-walled nanotubes [12,15-18], nanohorns [6,19,20], and graphene [21-23], were widely considered for solar energy applications. Carbon-based nanoadditives reach higher thermal conductivity enhancements at lower concentrations than other families of nanoparticles (metals, metal oxides). Moreover, the dispersion of carbon-based nanoadditives on a base fluid usually causes its conversion into a dark fluid. Graphene stands out as one of the most interesting carbon allotropes [24], thanks to its high thermal conductivity and its outstanding mechanical and electrical properties. However, graphene is hydrophobic, thus its stable dispersion in aqueous fluids is a difficult task. On the other hand, graphene oxide entails lower dispersability problem in water, but its thermal conductivity is dramatically reduced with respect to pristine graphene. A balance between dispersability in water and promising thermal properties is shown by reduced graphene oxide and functionalized graphene $[25,26]$. As for the nanoadditive morphology, it is worth noting that commercial multilayer structures of functionalized graphene, nanosheets or nanoplatelets partially retain the original properties of the single-layer form with a notably lower production cost [22].

Various studies have investigated the potential of nanofluids containing graphene derivatives as heat-transfer media. Vallejo et al. [27] measured the main thermophysical properties affecting the heat-transfer behaviour of a water/propylene glycol nanofluid containing functionalized graphene nanoplatelets. The authors highlighted that the $0.25 \mathrm{wt} \%$ nanoadditive concentration ensured the best compromise between thermal conductivity enhancement and viscosity increase. Similarly, Cabaleiro et al. [28] determined the thermophysical properties of sulfonic acid-functionalized graphene nanoplatelets dispersed in a mixture of ethylene glycol and water. Nevertheless, they found that, for the studied nanoparticle concentrations (up to $0.5 \mathrm{wt} \%$ ), the heat-transfer properties of the fluid did not improve considerably. Agromayor et al. [29] investigated the heat-transfer behaviour of a water-based nanofluid containing sulfonic acid-functionalized graphene nanoplatelets, using a tube-in-tube heat 
exchanger. They found that the $0.5 \mathrm{wt} \%$ nanoplatelet concentration represented the optimal loading for convective heat-transfer performance.

Although some studies addressed the optical properties of nanofluids containing graphene oxide [30], reduced graphene oxide [31], or even conventional graphene [32], very few researchers have specifically studied the potential of graphene nanoplatelets nanofluids as sunlight absorbers, which still remains an open research line [21,22].

As regards direct solar steam generation, various authors reported on the efficient solar steam generation by gold [33], silicon [34] and carbon nanostructures [13,35,36]. However, to the best of our knowledge, no research involving graphene nanoplatelets exploitation for direct solar steam generation has been addressed yet.

Preliminary investigations [21,22] have shown the promising perspectives for DASC and direct solar steam generation of low-concentration functionalized graphene nanoplatelet-based dispersions. Therefore, the present work completes the property assessment of these nanofluids, reporting on their detailed and comprehensive physical profile. Two different types of nanofluids, consisting of polycarboxylate chemically modified and sulfonic acid-functionalized graphene nanoplatelets dispersions in water at two nanoadditive concentrations, 0.005 and $0.05 \mathrm{wt} \%$, have been prepared and characterized. Elemental analyses of the employed nanopowders and $\mathrm{pH}$ studies of the dispersions were performed. The rheological behaviour and dynamic viscosity of the different-loaded nanofluids were determined in a wide temperature range. These analyses are directly related to the pumping power consumption in any working facility. Furthermore, the thermal conductivity of the samples was measured as well. This thermophysical property is directly involved in any heat-transfer process (also present in DASC systems). The volumetric behaviour of the nanofluids through the density determination was also characterized at various temperatures. Finally, a brief summary of the optical properties was included, new physical explanations being provided, to offer a comprehensive analysis of the designed nanofluids.

\section{Materials and Methods}

The different analysed nanofluids, $0.005 \mathrm{wt} \%$ and $0.05 \mathrm{wt} \%$ dispersions of sulfonic acid-functionalized graphene nanoplatelets (S-GnP), and polycarboxylate chemically modified graphene nanoplatelets (P-GnP, NanoInnova Technologies S.L., Madrid, Spain) in tridistilled water, W, were designed by a two-step method. Firstly, the required quantities of nanopowder and water were weighed in a balance Mettler AE-200 (Mettler Toledo, Greifensee, Switzerland), 0.1 mg uncertainty, and appropriately mixed. Then, the resulting mixtures were submitted to ultrasonication in an ultrasonic bath Ultrasounds (JP Selecta S.A., Barcelona, Spain) during $120 \mathrm{~min}$ at $20 \mathrm{kHz}$.

Elemental analyses (C, H, N, S and O) were performed by an elemental analyser Flash 2000 (Thermo Fisher Scientific, Cambridge, UK). For the C, H, N, S detection, around 1-2 mg of each dry nanopowder were placed in tin capsules. Then, the samples were subjected to combustion at $1173 \mathrm{~K}$, separating the subsequent combustion gases by column chromatography with He as carrier gas. Lastly, the presence of $\mathrm{CO}_{2}, \mathrm{H}_{2} \mathrm{O}, \mathrm{NO}_{2}$ and $\mathrm{SO}_{2}$ (corresponding to the presence of $\mathrm{C}, \mathrm{H}, \mathrm{N}$ and $\mathrm{S}$, respectively) were detected by an integrated thermal conductivity detector (TCD). For the O detection, around 1-2 mg of each nanoadditive were placed silver capsules. Then, the samples were submitted to pyrolysis at $1333 \mathrm{~K}$, separating the resulting gases by column chromatography with $\mathrm{He}$ as carrier gas. Finally, the presence of $\mathrm{O}$, combined with $\mathrm{C}$ as $\mathrm{CO}$, was chromatographically separated from other products and detected by TCD.

Dynamic light scattering (DLS) analyses to characterize the polydispersity of the nanoadditive were developed by a Zetasizer Nano ZS (Malvern Instruments Ltd., Malvern, UK). The $\mathrm{pH}$ of the different-loaded dispersions was assessed through a Sension $+\mathrm{PH} 3 \mathrm{pH}-$ meter (Hach, $\mathrm{CO}, \mathrm{USA})$ with a combination $\mathrm{pH}$ electrode, code 5010.

The rheological behaviour of the samples ( 283.15 to $323.15 \mathrm{~K}$ ) was studied by a rheometer Physica MCR 101 (Anton Paar, Graz, Austria) coupled with a cone-plate geometry CP50-1, determining the 
flow curves in the 10 to $1000 \mathrm{~s}^{-1}$ shear rate range. The expanded uncertainty $(\mathrm{k}=2)$ of the experimental dynamic viscosities is $3 \%[27,37]$.

Thermal conductivities ( $293.15 \mathrm{~K}$ ) were experimentally measured by the transient hot wire method through a KD2 Pro thermal analyzer (Decagon Devices, Pullman, WA, USA) coupled with a KS-1 probe. The expanded uncertainty $(\mathrm{k}=2)$ of these measurements is 3\% [27].

Densities for each nanofluid set $(288.15$ to $313.15 \mathrm{~K})$ were experimentally determined by a densimeter DMA 500 (Anton Paar, Graz, Austria) based on the oscillating U-tube technique. The expanded uncertainty $(\mathrm{k}=2)$ of these measurements is $0.1 \%[38,39]$.

To provide a comprehensive physical profile, linear and non-linear optical properties of the studied nanofluids were summarized from a previous study [21]. These properties were obtained by a commercial double beam ultraviolet-visible (UV-Vis) spectrophotometer Lambda 900 (PerkinElmer, Waltham, MA, USA) $[40,41]$ and a home-made laser experimental setup to perform high light-intensity tests. The main element of this setup, the light source, is a pulsed nanosecond Nd:YAG laser Q-smart 850 (Quantel, Les Ulis, France) that provides 6 ns pulses at three wavelengths (1064, 532 and $355 \mathrm{~nm}$ ). More details about the experimental apparatus can be found elsewhere [21].

\section{Results and Discussion}

\subsection{Nanopowder Chemical Composition and Nanofluids' Stability}

The employed nanopowders were morphologically and chemically characterized previously $[21,29,37,42,43]$. Atomic force microscopy analyses evidenced the structure of nanoplatelets (stacks of graphene sheets), with similar heights per sheet of 3 to $12 \mathrm{~nm}$ for S-GnP [42] and of 2 to $18 \mathrm{~nm}$ for P-GnP [43]. Transmission electron microscopy (TEM) analyses [21,37] showed that S-GnP particles are generally larger than P-GnP particles, with longer dimensions up to $590 \mathrm{~nm}$ and $500 \mathrm{~nm}$, respectively. Concerning to chemical composition, Energy-Dispersive X-ray Spectroscopy tests stated the existence of $\mathrm{C}, \mathrm{O}$ and $\mathrm{S}$ for S-GnP [29] and C, O and K for P-GnP [37].

Results of elemental analysis for nanopowders are shown in Table 1, establishing the relative amount of each element. For S-GnP, the major presence of $\mathrm{C}(69.1 \%)$ and $\mathrm{O}(12.6 \%)$ was confirmed but the presence of $\sim 5 \%$ of $\mathrm{S}$ and $\sim 3 \%$ of hydrogen $(\mathrm{H})$ and nitrogen $(\mathrm{N})$ was also detected. In the case of P-GnP, the presence of C (52.4\%) and O (22.4\%) was reaffirmed and a content of $\sim 2 \%$ of $\mathrm{H}$ was established.

Table 1. Results of elemental analyses for sulfonic acid-functionalized graphene nanoplatelets (S-GnP) and polycarboxylate chemically modified graphene nanoplatelets (P-GnP) nanopowders.

\begin{tabular}{ccc}
\hline Element & S-GnP & P-GnP \\
\hline C [\%] & 69.1 & 52.4 \\
H [\%] & 3.1 & 2.2 \\
N [\%] & 3.2 & 0 \\
S [\%] & 5.4 & 0 \\
O [\%] & 12.6 & 22.4 \\
Total [\%] & 93.4 & 77.0 \\
\hline
\end{tabular}

The stability of S-GnP and P-GnP aqueous nanofluids was studied previously [21] by DLS analyses of the averaged apparent size of the nanoadditives into the base fluid over the time and by Zeta potential studies. The DLS analyses over time confirmed that the initial characteristics of the dispersion were easily recoverable by a simple mechanical stirring. However, some sedimentation was detected for samples left in completely static conditions after one week, mainly for S-GnP samples [21].

In this work, the polydispersity of the S-GnP and P-GnP dispersions was characterized by DLS measurements through the size distribution by number. S-GnP nanoadditive (Figure 1a) presents higher apparent size than P-GnP nanoadditive (Figure 1b), in accordance with the previously stated information. 


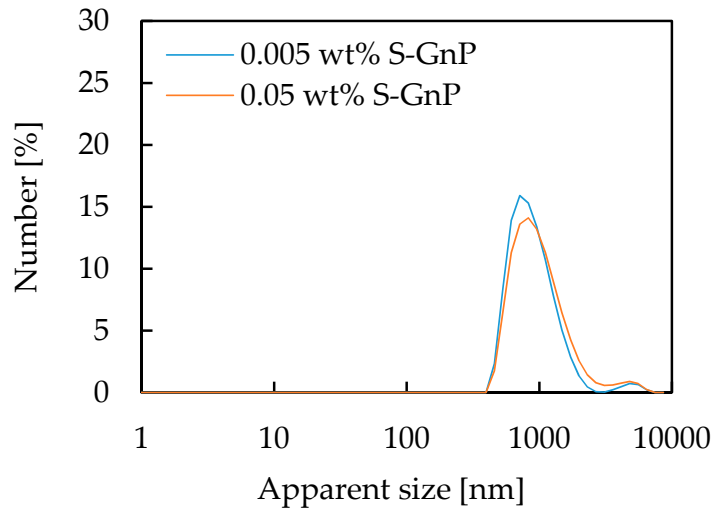

(a)

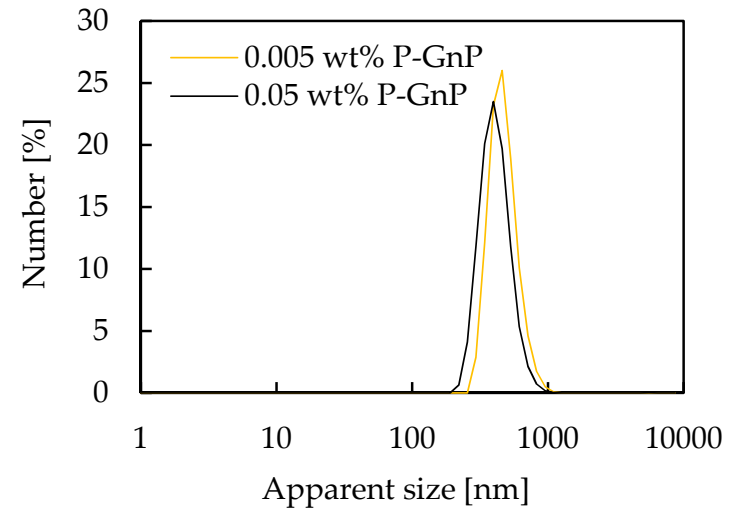

(b)

Figure 1. Size distribution by number for the S-GnP (a) and P-GnP (b) dispersions in water.

Furthermore, as it can be concluded comparing Figure 1a,b, P-GnP presents a narrower size distribution than S-GnP, which is a symptom of higher uniformity of size. This conclusion is reinforced by the obtained values of polydispersity index, which is also a measure of width of the particle size distribution [44,45]. According to the literature, monodispersed particles present values between 0.01 and $0.5-0.7$ while samples with very broad size distribution present values over 0.7 (also a first symptom of unstable dispersions) [44,45]. Values of $0.41-0.44$ and $0.28-0.32$ were obtained for the S-GnP and P-GnP nanofluids, respectively. It can be also observed that there are not significant concentration dependences on the polydispersity within the studied nanoadditive loading range.

The force of the electrostatic repulsions among the dispersed particles counteracts with that of the attractions that provoke agglomeration and precipitation. These forces are largely dependent on the distance of the $\mathrm{pH}$ from the isoelectric point [46,47]. Zeta potential values of 44 and $-53 \mathrm{mV}$ were obtained for S-GnP and P-GnP dispersions in water, respectively [21], synonymous of moderate/good stability according to literature criteria [48]. These values also indicate that the analysed nanofluids are far away from the isoelectric point. At the same time, extremely acid working fluids should be avoided to prevent the corrosion of facilities.

Table 2 shows the effect of the nanoparticle addition to the $\mathrm{pH}$. The dispersion of both types of different-functionalized graphene nanoplatelets implicates acidification of the base fluid, soft for P-GnP and moderate for S-GnP.

Table 2. $\mathrm{pH}$ values of the different-loaded nanofluids at room temperature.

\begin{tabular}{cc}
\hline Sample & pH \\
\hline $\mathrm{W}$ & 6.2 \\
$0.005 \mathrm{wt} \% \mathrm{~S}-\mathrm{GnP} / \mathrm{W}$ & 4.3 \\
$0.05 \mathrm{wt} \% \mathrm{~S}-\mathrm{GnP} / \mathrm{W}$ & 3.3 \\
$0.005 \mathrm{wt} \% \mathrm{P}-\mathrm{GnP} / \mathrm{W}$ & 5.2 \\
$0.05 \mathrm{wt} \% \mathrm{P}-\mathrm{GnP} / \mathrm{W}$ & 5.0 \\
\hline
\end{tabular}

\subsection{Rheological and Thermophysical Properties}

The flow curves of the different-loaded nanofluids at two temperatures are presented in Figure 2. It evidences a Newtonian nature for all samples The dynamic viscosities of the samples were considered as the mean values in the 10 to $1000 \mathrm{~s}^{-1}$ shear rate range. The experimental dynamic viscosities for the base fluid in the 283.15 to $323.15 \mathrm{~K}$ present deviations lower than $2.5 \%$ with respect to literature data [49-53]. 


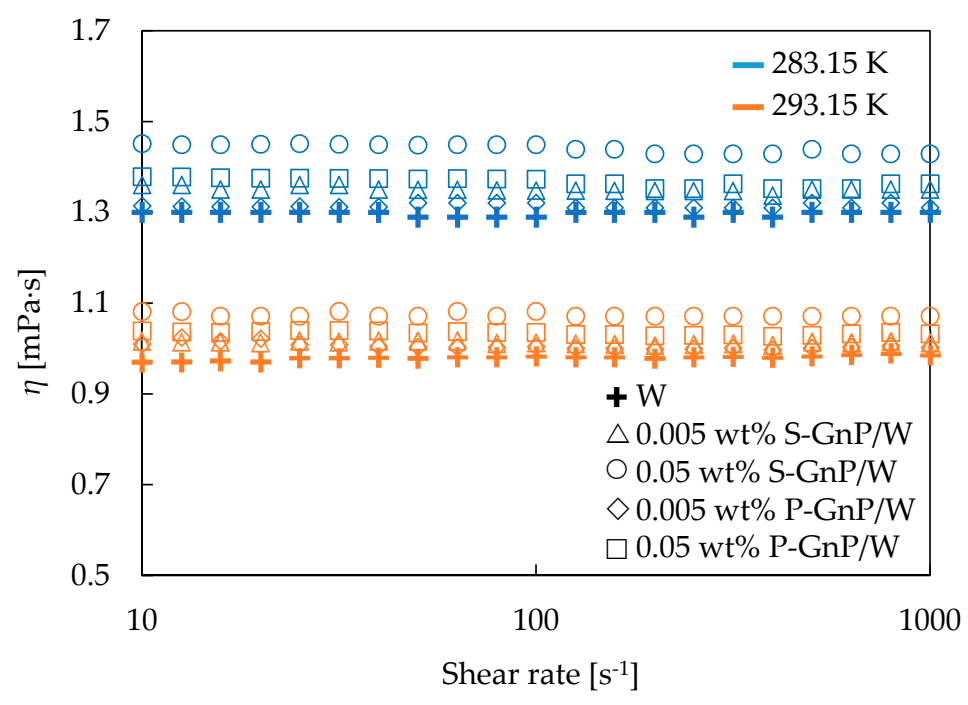

Figure 2. Flow curves for the different loaded S-GnP and P-GnP nanofluids in the 10 to $1000 \mathrm{~s}^{-1}$ shear rate range at $283.15 \mathrm{~K}$ (blue) and $293.15 \mathrm{~K}$ (orange).

Table 3 shows the dynamic viscosity values for water and the S-GnP and P-GnP nanofluids, evidencing a 59\% decrease with the increasing temperature in the $40 \mathrm{~K}$ analysed range for all samples. This same temperature behaviour for the base fluid and the different nanofluids was also reported previously $[42,43,54]$. The increasing temperature over a fluid causes a decrease of the cohesive intermolecular forces among molecules, producing a viscosity reduction [43,55]. The dispersion of nanoadditives does not alter these relative variations at the analysed concentrations.

Table 3. Dynamic viscosity values for the different loaded S-GnP and P-GnP nanofluids at temperatures from 283.15 to $323.15 \mathrm{~K}$.

\begin{tabular}{cccccc}
\hline & \multicolumn{5}{c}{$\eta[\mathbf{m P a} \cdot \mathbf{s}]$} \\
\cline { 2 - 6 } Temperature [K] & $\mathbf{W}$ & $\begin{array}{c}\mathbf{0 . 0 0 5} \mathbf{w t} \% \\
\text { S-GnP/W }\end{array}$ & $\begin{array}{c}\mathbf{0 . 0 5} \mathbf{w t} \% \\
\text { S-GnP/W }\end{array}$ & $\begin{array}{c}\mathbf{0 . 0 0 5} \mathbf{w t} \% \\
\mathbf{P - G n P / W}\end{array}$ & $\begin{array}{c}\mathbf{0 . 0 5} \mathbf{w t} \% \\
\mathbf{P - G n P / W}\end{array}$ \\
\hline 283.15 & 1.298 & 1.350 & 1.429 & 1.315 & 1.356 \\
293.15 & 0.986 & 1.014 & 1.071 & 1.002 & 1.031 \\
303.15 & 0.787 & 0.821 & 0.860 & 0.796 & 0.816 \\
313.15 & 0.639 & 0.662 & 0.696 & 0.647 & 0.664 \\
323.15 & 0.535 & 0.553 & 0.587 & 0.539 & 0.561 \\
\hline
\end{tabular}

Increases with the rising nanoadditive concentration are observed for both nanofluid sets. Viscosity is usually defined as the internal friction of fluids caused by the molecular cohesion that provokes resistance to flow [56]. The dispersion of nanoadditives in a fluid leads to a higher level of friction, which implies a greater resistance to flow and consequently higher viscosities. These slight increases for the analysed concentrations show maximum values of $10 \%$ and $4.9 \%$ for S-GnP and P-GnP dispersions, respectively. Note that the reported increases for S-GnP are twice as high as those for P-GnP. Figure 3 shows the dynamic viscosity increases in relation to the base fluid for the different-loaded nanofluids. These increases appear almost temperature-independent in the whole analysed temperature range, as we also previously pointed out for other samples [43]. 


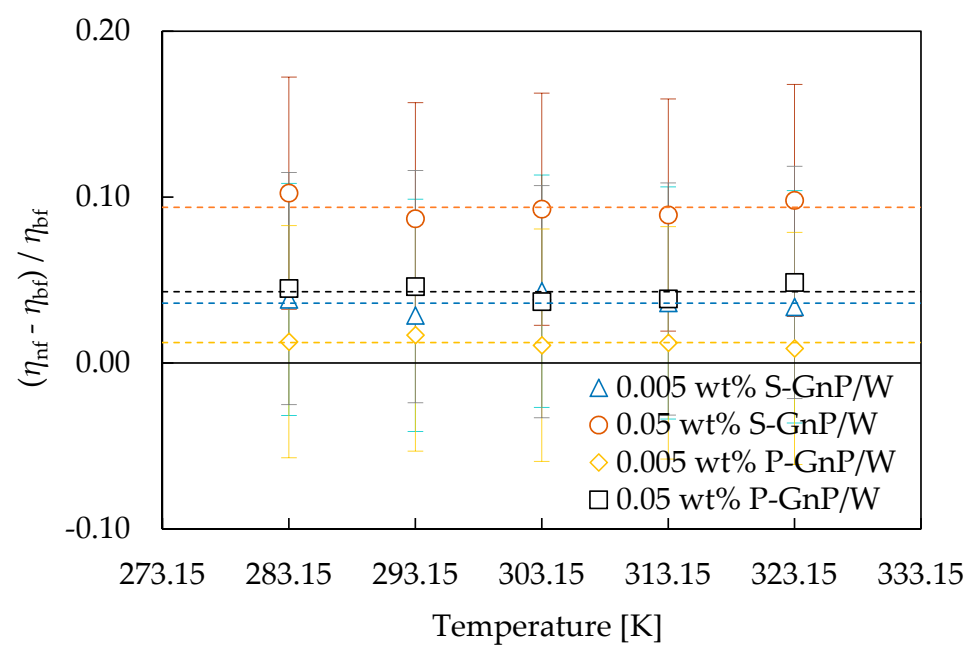

Figure 3. Dynamic viscosity increases for the different S-GnP and P-GnP nanofluids at temperatures from 283.15 to $323.15 \mathrm{~K}$.

The experimental thermal conductivities for all the designed nanofluids at $293.15 \mathrm{~K}$ practically reproduce the same value of the base fluid, $598 \mathrm{~mW} \cdot \mathrm{m}^{-1} \cdot \mathrm{K}^{-1}$, with deviations below $0.3 \%$ in all cases, much lower than the experimental uncertainty of the measurements. Therefore, it can be affirmed that the selected low concentrations do not entail effective thermal conductivity variations with respect to the pure base fluid.

Figure 4 shows the temperature dependence of density for all the samples, compared with that measured in the case of pure water. The experimental density values for the base fluid at temperatures from 283.15 to $323.15 \mathrm{~K}$ agree well with literature, maintaining deviations below $0.08 \%$ [51]. On the other hand, from Figure 3 we obtain that, for all samples, the density decreases with the increasing temperature of $0.7 \%$ within the analysed temperature range. As regards the density behaviour with increasing nanoadditive concentration, the variations between the different-loaded samples lie within the experimental uncertainty in all cases. Nevertheless, it can be pointed out that all nanofluids showed slight systematic higher values than the base fluid that reach a $0.07 \%$ increase for the $0.05 \mathrm{wt} \%$ $\mathrm{S}-\mathrm{GnP}$ nanofluid. Furthermore, the small increases are always higher for S-GnP than for P-GnP for the same concentration.

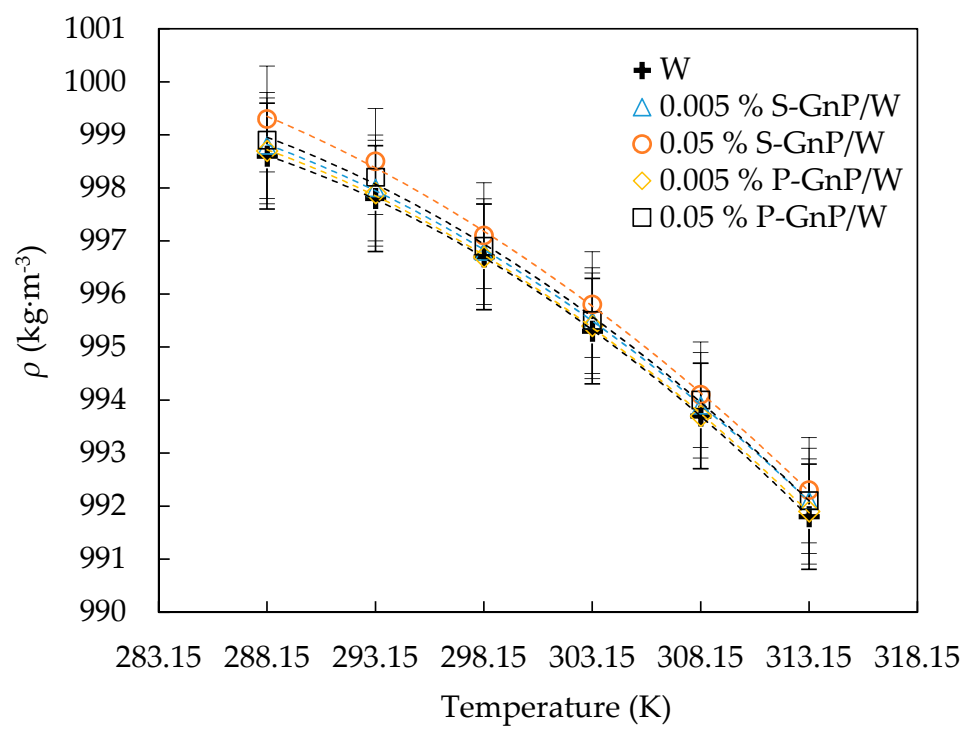

Figure 4. Densities at various temperatures for the different loaded S-GnP and P-GnP nanofluids. 


\subsection{Optical Properties}

The optical behaviour of nanodispersions is a key parameter to take into account for the proposed solar energy application. Therefore, this paragraph briefly summarizes the results of the comparative optical characterization of S- and P-GnP-based nanofluids, studied at both low- and high-intensity irradiation regimes. More details of these investigations can be found in Reference [21].

First, it is interesting to underline that some spectral differences exist among samples due to the different nanoadditive types. The shape of the UV plasmonic peak and of its tail appears different for the two dispersions, consistent with the dissimilar functionalization [21]. Both nanoadditives, even at the considered low concentrations, remarkably reduce the transmittance in relation to water in the whole investigated range, but P-GnP samples show a generalized higher extinction coefficient than S-GnP samples, resulting in a better solar absorber. As for the effect of concentration, it is worth mentioning that increasing the mass loading of nanoadditives causes the extinction coefficient to grow, although this trend is not exactly proportional to the mass ratios.

The knowledge of the extinction coefficient $\mu(\lambda)$ allows us to estimate the sunlight extinction fraction $(E F)$, corresponding to the fraction of the incident sunlight $I(\lambda)$ [57] that is absorbed by the liquid through a propagation path of length, $x$, according to the following equation $[58,59]$ :

$$
E F(x)=1-\frac{\int_{\lambda_{\min }}^{\lambda_{\operatorname{MAX}}} I(\lambda) \cdot e^{-\mu(\lambda) x} d \lambda}{\int_{\lambda_{\min }}^{\lambda_{M A X}} I(\lambda) d \lambda}
$$

where $\lambda_{\text {MAX }}$ and $\lambda_{\min }$ and are the maximum and minimum wavelength, 300 and $2500 \mathrm{~nm}$, respectively. Sunlight results completely extinguished $(E F=1)$ within the first $5 \mathrm{~mm}$ of the sample in case of the P-GnP nanofluid, while it takes about $25 \mathrm{~mm}$ for that of the S-GnP. As a term of comparison, pure water shows an EF value lower than 0.4 after a propagation path as long as $50 \mathrm{~mm}$. Non-linear optical properties of nanofluids are also of interest, considering that the energy densities achievable in our experiments are compatible with solar concentration systems, allowing to evaluate possible further applications of these nanofluids in solar vapor generation and solar desalination. Therefore, the sample transmittance at high light input intensities was measured. Due to the characteristics of the setup, the experiments were possible only on the $0.005 \mathrm{wt} \%$ concentration. In fact, the samples featuring the highest investigated nanoadditive loading $(0.05 \mathrm{wt} \%)$ turned out to prevent any transmission of the input laser beam in the 10-mm long optical cell.

Figure 5 reports the results concerning the non-linear behavior of the two different kinds of nanofluids, for three considered wavelengths. The P-GnP samples often result in a considerably lower non-linear transmittance if compared with the corresponding S-GnP nanofluids, according to the comparison between linear extinction coefficients. The more pronounced non-linearity is always at $355 \mathrm{~nm}$ and the less pronounced is at $532 \mathrm{~nm}$, with the $1064 \mathrm{~nm}$ showing an intermediate behavior. Interestingly, the relative wavelengths trend does not reflect the relative values of linear extinction coefficient, deserving further investigations. At higher input energies (not shown in Figure 5) the $1064 \mathrm{~nm}$ curves change the concavity, resulting in a non-monotonic behavior. This effect could be explained by a damage occurring in the nanostructures, as already hypothesized in other studies for different carbon derivatives [60]. 


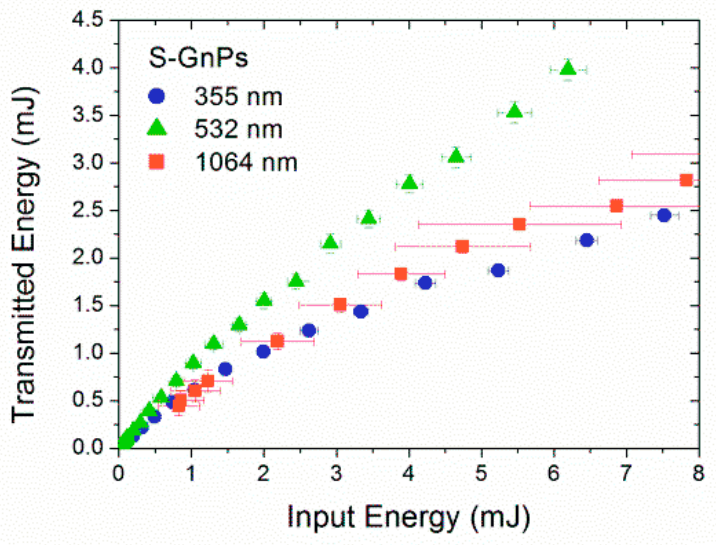

(a)

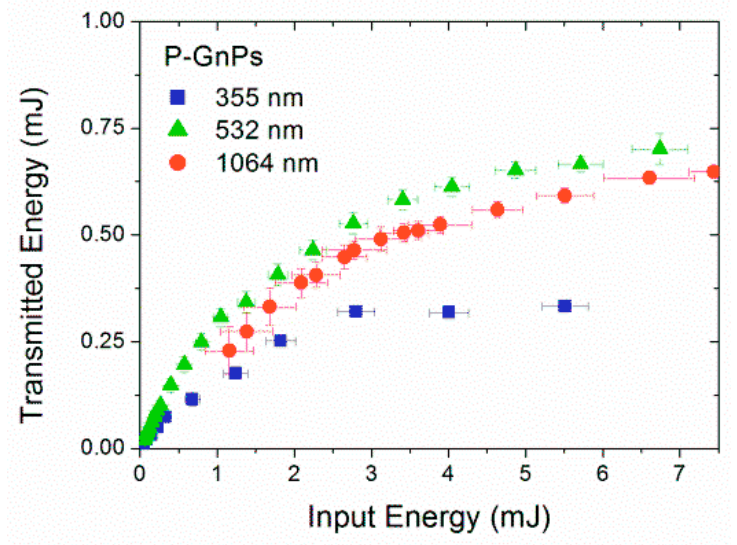

(b)

Figure 5. Transmitted energy as a function of the incident energy in the non-linear regime, for both S-GnPs (a) and P-GnPs nanofluids (b).

A fitting numerical procedure according to semi-empirical models linking the output energy from the nanofluid, $E_{\text {out }}$, to incident energy $E_{\text {in }}$ allowed us to identify, for the samples showing monotonic curves (i.e., those at 355 and $532 \mathrm{~nm}$ wavelengths), the occurring mechanism, non-linear absorption (Equation (2)) or non-linear scattering (Equation (3)), which is responsible of the observed results [61-63].

$$
\begin{gathered}
E_{\text {out }}=\frac{T_{s}^{2} e^{-\mu L} E_{\text {in }}}{1+0.1 E_{\text {in }} / E_{t}}, \\
E_{\text {out }}=T_{s}^{2} E_{t} e^{-\mu L}\left(1+\frac{\mu^{e}}{\mu}\left(\frac{E_{\text {in }}}{E_{t}}-1\right)\right)^{\frac{\mu}{\mu^{e}}}
\end{gathered}
$$

where $T_{S}$ is a coefficient connected to the transmittance of the cuvette and $L$ the optical path length $(10 \mathrm{~mm})$. The fitting parameters are $E_{t}$, the energy threshold for each non-linear process and $\mu_{e}$, the non-linear contribution to extinction coefficient due to the scattering by vapor bubbles created in the liquid.

Non-linear absorption (Equation (2)) could be identified as the acting mechanism at $355 \mathrm{~nm}$ for both P- and S-type nanoadditives and at $532 \mathrm{~nm}$ for P-GnP, while both models (Equations (2) and (3)) could be acceptable for S-GnP at $532 \mathrm{~nm}$. Therefore, non-linearity at a concentration of $0.005 \mathrm{wt} \%$ and at 355 and $532 \mathrm{~nm}$ is always of electronic origin in P-GnP samples, while for S-GnP samples a non-linear scattering contribution could appear at $532 \mathrm{~nm}$. The non-monotonic and more markedly non-linear trends, which were evidenced at $1064 \mathrm{~nm}$, suggest the coincidence of simultaneous non-linear mechanisms as the generation of bubbles.

A quantitative assessment of the occurrence of bubbles was not possible due to limitations of the experimental apparatus. It can be pointed out that no significant temperature increases of the nanofluids were detected during the time of intermittent laser irradiation, about 20 min per test. The nanoparticles, with a much stronger light absorption than the surrounding liquid, could act as a localized source of heat, quickly heating the surrounding fluid and causing vapour transition. A deeper study of this effect has interesting prospects for further investigations.

\section{Conclusions}

In this study, a comparative analysis of two different nanofluid sets was developed. S-GnP and P-GnP dispersions in water at 0.005 and $0.05 \mathrm{wt} \%$ for solar applications were evaluated by rheological, thermophysical and optical experimental studies. Elemental analyses for the commercial nanopowders evidenced the major presence of $\mathrm{C}$ and $\mathrm{O}$ in both cases. $\mathrm{pH}$ studies revealed that the dispersion 
of both differently functionalized graphene nanoplatelets involves an acidification of water that is more prominent for S-GnP. The rheological analyses showed Newtonian behavior for all studied nanofluids, with temperature-independent dynamic viscosity increases by the nanoadditive loading. These modifications reach $10 \%$ and $4.9 \%$ for the highest concentrations of S-GnP and P-GnP, respectively. The selected low concentrations for solar applications do not involve effective thermal conductivity differences with respect to the base fluid. Slight density increases with nanoadditive loading were observed with a maximum $0.07 \%$ enhancement for the $0.05 \mathrm{wt} \% \mathrm{~S}-\mathrm{GnP}$ nanofluid. The spectral extinction coefficient results in being considerably increased in nanofluids with respect to water, with nanoadditive-dependent spectral features and a larger effect for P-GnP. For the $0.05 \%$ nanoadditive concentration, the extinction of sunlight is complete after $5 \mathrm{~mm}$ and $25 \mathrm{~mm}$ propagation in P- and S-GnP dispersions, respectively. Both nanoadditive types evidenced an optically non-linear behavior at high input intensities at the three investigated laser wavelengths (355, 532 and $1064 \mathrm{~nm})$, more pronounced in P-GnP samples. A numerical fitting described the electronic origin of non-linearity at $355 \mathrm{~nm}$ in both nanoadditives, which was also confirmed at $532 \mathrm{~nm}$ in P-GnP samples, while for S-GnP samples, a non-linear scattering contribution could appear. The more marked non-linear trends in the infrared suggest the coincidence of concurrent mechanisms as the production of bubbles. Thus, the proposed nanofluids present moderate long-term stabilities, low dynamic viscosity increases with respect to the base fluid (synonym of low pumping power rises), similar densities and thermal conductivities than the base fluid and huge modifications of its optical profile, with the appearance of non-linear mechanisms as the generation of bubbles under high laser irradiation. The powers reached by the laser are comparable with those achieved in concentrated solar power, opening the potential application of the designed nanofluids in solar desalination or vapor generation.

Author Contributions: J.P.V. designed the nanofluids. E.S., J.P.V. and L.L. conceived the study and designed the experimental procedure. E.S., J.P.V., L.M., M.R.M. and D.D.R. performed the experimental measurements. A.D. wrote the numerical fitting code and developed the simulations. E.S. and J.P.V. analyzed the data and, together with D.D.R. wrote the original draft of the manuscript. E.S., J.P.V., L.M. and L.L performed the writing-review and editing. All authors read and approved the final manuscript.

Funding: This work was partially supported by COST Action CA15119: Overcoming Barriers to Nanofluids Market Uptake (Nanouptake) in the framework of the Short-Term Scientific Mission program. This work was also partially supported by "Ministerio de Economía y Competitividad" (Spain) and FEDER program through ENE2017-86425-C2-1-R project. J.P.V. acknowledges FPI Program of "Ministerio de Economía y Competitividad".

Acknowledgments: The authors acknowledge M. D'Uva and M. Pucci (INO-CNR) for technical assistance.

Conflicts of Interest: The authors declare no conflict of interest.

\section{References}

1. Choi, S.U.S.; Eastman, J.A. Enhancing Thermal Conductivity of Fluids with Nanoparticles. In Proceedings of the 1995 International Mechanical Engineering Congress and Exhibition, San Francisco, CA, USA, 12-17 November 1995.

2. Patil, M.S.; Seo, J.H.; Kang, S.J.; Lee, M.Y. Review on synthesis, thermo-physical property, and heat transfer mechanism of nanofluids. Energies 2016, 9, 840. [CrossRef]

3. Bellos, E.; Tzivanidis, C. Optimization of a solar-driven trigeneration system with nanofluid-based parabolic trough collectors. Energies 2017, 10, 848. [CrossRef]

4. Lee, J.H.; Hwang, S.G.; Lee, G.H. Efficiency Improvement of a Photovoltaic Thermal (PVT) System Using Nanofluids. Energies 2019, 12, 3063. [CrossRef]

5. Minardi, J.E.; Chuang, H.N. Performance of a "black" liquid flat-plate solar collector. Sol. Energy 1975, 17, 179-183. [CrossRef]

6. Bortolato, M.; Dugaria, S.; Agresti, F.; Barison, S.; Fedele, L.; Sani, E.; Del Col, D. Investigation of a single wall carbon nanohorn-based nanofluid in a full-scale direct absorption parabolic trough solar collector. Energy Convers. Manag. 2017, 150, 693-703. [CrossRef]

7. Lin, M.; Reinhold, J.; Monnerie, N.; Haussener, S. Modeling and design guidelines for direct steam generation solar receivers. Appl. Energy 2018, 216, 761-776. [CrossRef] 
8. Bouvier, J.-L.; Michaux, G.; Salagnac, P.; Nepveu, F.; Rochier, D.; Kientz, T. Experimental characterisation of a solar parabolic trough collector used in a micro-CHP (micro-cogeneration) system with direct steam generation. Energy 2015, 83, 474-485. [CrossRef]

9. Taylor, R.A.; Phelan, P.E.; Adrian, R.J.; Gunawan, A.; Otanicar, T.P. Characterization of light-induced, volumetric steam generation in nanofluids. Int. J. Therm. Sci. 2012, 56, 1-11. [CrossRef]

10. Sani, E.; Papi, N.; Mercatelli, L.; Żyła, G. Graphite/diamond ethylene glycol-nanofluids for solar energy applications. Renew. Energy 2018, 126, 692-698. [CrossRef]

11. Wang, X.; He, Y.; Liu, X.; Shi, L.; Zhu, J. Investigation of photothermal heating enabled by plasmonic nanofluids for direct solar steam generation. Sol. Energy 2017, 157, 35-46. [CrossRef]

12. Wang, X.; He, Y.; Cheng, G.; Shi, L.; Liu, X.; Zhu, J. Direct vapor generation through localized solar heating via carbon-nanotube nanofluid. Energy Convers. Manag. 2016, 130, 176-183. [CrossRef]

13. Ni, G.; Miljkovic, N.; Ghasemi, H.; Huang, X.; Boriskina, S.V.; Lin, C.T.; Wang, J.; Xu, Y.; Rahman, M.M.; Zhang, T.J.; et al. Volumetric solar heating of nanofluids for direct vapor generation. Nano Energy 2015, 17, 290-301. [CrossRef]

14. Gorji, T.B.; Ranjbar, A.A. Thermal and exergy optimization of a nanofluid-based direct absorption solar collector. Renew. Energy 2017, 106, 274-287. [CrossRef]

15. Hordy, N.; Rabilloud, D.; Meunier, J.-L.; Coulombe, S. High temperature and long-term stability of carbon nanotube nanofluids for direct absorption solar thermal collectors. Sol. Energy 2014, 105, 82-90. [CrossRef]

16. Karami, M.; Akhavan Bahabadi, M.A.; Delfani, S.; Ghozatloo, A. A new application of carbon nanotubes nanofluid as working fluid of low-temperature direct absorption solar collector. Sol. Energy Mater. Sol. Cells 2014, 121, 114-118. [CrossRef]

17. Delfani, S.; Karami, M.; Akhavan-Behabadi, M.A. Performance characteristics of a residential-type direct absorption solar collector using MWCNT nanofluid. Renew. Energy 2016, 87, 754-764. [CrossRef]

18. Boldoo, T.; Ham, J.; Cho, H. Comparison Study on Photo-Thermal Energy Conversion Performance of Functionalized and Non-Functionalized MWCNT Nanofluid. Energies 2019, 12, 3763. [CrossRef]

19. Moradi, A.; Sani, E.; Simonetti, M.; Francini, F.; Chiavazzo, E.; Asinari, P. Carbon-Nanohorn Based Nanofluids for a Direct Absorption Solar Collector for Civil Application. J. Nanosci. Nanotechnol. 2015, 15, 3488-3495. [CrossRef]

20. Dugaria, S.; Bortolato, M.; Del Col, D. Modelling of a direct absorption solar receiver using carbon based nanofluids under concentrated solar radiation. Renew. Energy 2018, 128, 495-508. [CrossRef]

21. Vallejo, J.P.; Mercatelli, L.; Martina, M.R.; Di Rosa, D.; Dell'Oro, A.; Lugo, L.; Sani, E. Comparative study of different functionalized graphene-nanoplatelet aqueous nanofluids for solar energy applications. Renew. Energy 2019, 141, 791-801. [CrossRef]

22. Sani, E.; Vallejo, J.P.; Cabaleiro, D.; Lugo, L. Functionalized graphene nanoplatelet-nanofluids for solar thermal collectors. Sol. Energy Mater. Sol. Cells 2018, 185, 205-209. [CrossRef]

23. Xiao, X.; Zhang, G.; Ding, Y.; Wen, D. Rheological Characteristics of Molten Salt Seeded with $\mathrm{Al}_{2} \mathrm{O}_{3}$ Nanopowder and Graphene for Concentrated Solar Power. Energies 2019, 12, 467. [CrossRef]

24. Geim, A.K.; Novoselov, K.S. The rise of graphene. Nat. Mater. 2007, 6, 183-191. [CrossRef] [PubMed]

25. Si, Y.; Samulski, E.T. Synthesis of water soluble graphene. Nano Lett. 2008, 8, 1679-1682. [CrossRef] [PubMed]

26. Park, S.; An, J.; Piner, R.D.; Jung, I.; Yang, D.; Velamakanni, A.; Nguyen, S.T.; Ruoff, R.S. Aqueous suspension and characterization of chemically modified graphene sheets. Chem. Mater. 2008, 20, 6592-6594. [CrossRef]

27. Vallejo, J.P.; Pérez-Tavernier, J.; Cabaleiro, D.; Fernández-Seara, J.; Lugo, L. Potential heat transfer enhancement of functionalized graphene nanoplatelet dispersions in a propylene glycol-water mixture. Thermophysical profile. J. Chem. Thermodyn. 2018, 123, 174-184. [CrossRef]

28. Cabaleiro, D.; Colla, L.; Barison, S.; Lugo, L.; Fedele, L.; Bobbo, S. Heat Transfer Capability of (Ethylene Glycol + Water)-Based Nanofluids Containing Graphene Nanoplatelets: Design and Thermophysical Profile. Nanoscale Res. Lett. 2017, 12, 53. [CrossRef]

29. Agromayor, R.; Cabaleiro, D.; Pardinas, A.A.; Vallejo, J.P.; Fernandez-Seara, J.; Lugo, L. Heat Transfer Performance of Functionalized Graphene Nanoplatelet Aqueous Nanofluids. Materials 2016, 9, 455. [CrossRef]

30. Chen, L.; Xu, C.; Liu, J.; Fang, X.; Zhang, Z. Optical absorption property and photo-thermal conversion performance of graphene oxide/water nanofluids with excellent dispersion stability. Sol. Energy 2017, 148, 17-24. [CrossRef] 
31. Chen, L.; Liu, J.; Fang, X.; Zhang, Z. Reduced graphene oxide dispersed nanofluids with improved photo-thermal conversion performance for direct absorption solar collectors. Sol. Energy Mater. Sol. Cells 2017, 163, 125-133. [CrossRef]

32. Zhang, L.; Chen, L.; Liu, J.; Fang, X.; Zhang, Z. Effect of morphology of carbon nanomaterials on thermo-physical characteristics, optical properties and photo-thermal conversion performance of nanofluids. Renew. Energy 2016, 99, 888-897. [CrossRef]

33. Neumann, O.; Feronti, C.; Neumann, A.D.; Dong, A.; Schell, K.; Lu, B.; Kim, E.; Quinn, M.; Thompson, S.; Grady, N.; et al. Compact solar autoclave based on steam generation using broadband light-harvesting nanoparticles. Proc. Natl. Acad. Sci. USA 2013, 110, 11677-11681. [CrossRef] [PubMed]

34. Ishii, S.; Sugavaneshwar, R.P.; Chen, K.; Dao, T.D.; Nagao, T. Solar water heating and vaporization with silicon nanoparticles at mie resonances. Opt. Mater. Express 2016, 6, 640-648. [CrossRef]

35. Wang, J.; Blau, W.J. Optical Limiting Properties of Single-Walled Carbon Nanotube Dispersions in Amide Solvents. In Proceedings of the SPIE 6988, Nanophotonics II, Strasbourg, France, 23 April 2008; p. 69881F.

36. Ghasemi, H.; Ni, G.; Marconnet, A.M.; Loomis, J.; Yerci, S.; Miljkovic, N.; Chen, G. Solar steam generation by heat localization. Nat. Commun. 2014, 5, 1-7. [CrossRef]

37. Vallejo, J.P.; Álvarez-Regueiro, E.; Cabaleiro, D.; Fernández-Seara, J.; Fernández, J.; Lugo, L. Functionalized graphene nanoplatelet nanofluids based on a commercial industrial antifreeze for the thermal performance enhancement of wind turbines. Appl. Therm. Eng. 2019, 152, 113-125. [CrossRef]

38. Żyła, G.; Vallejo, J.P.; Fal, J.; Lugo, L. Nanodiamonds—Ethylene Glycol nanofluids: Experimental investigation of fundamental physical properties. Int. J. Heat Mass Transf. 2018, 121, 1201-1213. [CrossRef]

39. Żyła, G.; Vallejo, J.P.; Lugo, L. Isobaric heat capacity and density of ethylene glycol based nanofluids containing various nitride nanoparticle types: An experimental study. J. Mol. Liq. 2018, 261, 530-539. [CrossRef]

40. Sani, E.; Dell'Oro, A. Spectral optical constants of ethanol and isopropanol from ultraviolet to far infrared. Opt. Mater. 2016, 60, 137-141. [CrossRef]

41. Sani, E.; Dell'Oro, A. Optical Constants of Ethylene Glycol over an Extremely Wide Spectral Range. Opt. Mater. 2014, 37, 36-41. [CrossRef]

42. Vallejo, J.P.; Gómez-Barreiro, S.; Cabaleiro, D.; Gracia-Fernández, C.; Fernández-Seara, J.; Lugo, L. Flow behaviour of suspensions of functionalized graphene nanoplatelets in propylene glycol-water mixtures. Int. Commun. Heat Mass Transf. 2018, 91, 150-157. [CrossRef]

43. Vallejo, J.P.; Żyła, G.; Fernández-Seara, J.; Lugo, L. Rheological behaviour of functionalized graphene nanoplatelet nanofluids based on water and propylene glycol: Water mixtures. Int. Commun. Heat Mass Transf. 2018, 99, 43-53. [CrossRef]

44. Nidhin, M.; Indumathy, R.; Sreeram, K.J.; Nair, B.U. Synthesis of iron oxide nanoparticles of narrow size distribution on polysaccharide templates. Bull. Mater. Sci. 2008, 31, 93-96. [CrossRef]

45. Das, P.K.; Mallik, A.K.; Ganguly, R.; Santra, A.K. Synthesis and characterization of $\mathrm{TiO}_{2}-$ water nanofluids with different surfactants. Int. Commun. Heat Mass 2016, 75, 341-348. [CrossRef]

46. Ghadimi, A.; Saidur, R.; Metselaar, H.S.C. A review of nanofluid stability properties and characterization in stationary conditions. Int. J. Heat Mass Transf. 2011, 54, 4051-4068. [CrossRef]

47. Huang, J.; Wang, X.; Long, Q.; Wen, X.; Zhou, Y.; Li, L. Influence of $\mathrm{pH}$ on the Stability Characteristics of Nanofluids. In Proceedings of the 2009 Symposium on Photonics and Optoelectronics, Wuhan, China, 14-16 August 2009.

48. Babita; Sharma, S.K.; Gupta, S.M. Preparation and evaluation of stable nanofluids for heat transfer application: A review. Exp. Therm. Fluid Sci. 2016, 79, 202-212. [CrossRef]

49. Hodgman, C.D. Handbook of Chemistry and Physics; Chemical Rubber Company: Boca Raton, FL, USA, 1976.

50. Deckwer, W.D. Density, Viscosity, Vapor Pressure, and Hydrogen Solubility of Aqueous Manganese (II) Sulfate Solutions. J. Chem. Eng. Data 1980, 25, 75-76. [CrossRef]

51. James, C.J.; Mulcahy, D.E.; Steel, B.J. Viscometer calibration standards: Viscosities of water between 0 and 60 degrees $C$ and of selected aqueous sucrose solutions at 25 degrees $C$ from measurements with a flared capillary viscometer. J. Phys. D Appl. Phys. 1984, 17, 225-230. [CrossRef]

52. Hartono, A.; Svendsen, H.F. Density, viscosity, and excess properties of aqueous solution of diethylenetriamine (DETA). J. Chem. Thermodyn. 2009, 41, 973-979. [CrossRef] 
53. Lemmon, E.W.; Huber, M.L.; McLinden, M.O. Reference Fluid Thermodynamic and Transport Properties (REFPROP), National Institute of Standards and Technology. In Nist Standard Reference Database 23; NIST: Gaithersburg, MD, USA, 2010.

54. Vallejo, J.P.; Żyła, G.; Fernández-Seara, J.; Lugo, L. Influence of Six Carbon-Based Nanomaterials on the Rheological Properties of Nanofluids. Nanomaterials 2019, 9, 146. [CrossRef]

55. Douglas, J.F.; Gasiorek, J.M.; Swaffield, J.A.; Jack, L.B. Fluid Mechanics; Prentice Hall: Upper Saddle River, NJ, USA, 2005.

56. Dembicki, H., Jr. Interpreting crude oil and natural gas data. In Practical Petroleum Geochemistry for Exploration and Production; Elsevier: Amsterdam, the Netherlands, 2017; pp. 135-188.

57. ASTM G173-03(2012), Standard Tables for Reference Solar Spectral Irradiances: Direct Normal and Hemispherical on $37^{\circ}$ Tilted Surface; ASTM International: West Conshohocken, PA, USA, 2012.

58. Sani, E.; Mercatelli, L.; Barison, S.; Pagura, C.; Agresti, F.; Colla, L.; Sansoni, P. Potential of carbon nanohorn-based suspensions for solar thermal collectors. Sol. Energy Mater. Sol. Cells 2011, 95, $2994-3000$. [CrossRef]

59. Sani, E.; Barison, S.; Pagura, C.; Mercatelli, L.; Sansoni, P.; Fontani, D.; Jafrancesco, D.; Francini, F. Carbon nanohorns-based nanofluids as direct sunlight absorbers. Opt. Express 2010, 18, 5179-5187. [CrossRef] [PubMed]

60. Sani, E.; Papi, N.; Mercatelli, L.; Barison, S.; Agresti, F.; Rossi, S.; Dell'Oro, A. Optical Limiting of Carbon Nanohorn-Based Aqueous Nanofluids: A Systematic Study. Nanomaterials 2020. submitted.

61. Hagan, D.J.; Xia, T.J.; Said, A.A.; Van Stryland, E.W. Tandem Limiter Optimization. In Proceedings of the SPIE 2229, Nonlinear Optical Materials for Switching and Limiting, Orlando, FL, USA, 6 July 1994.

62. Vincent, D.; Cruickshank, J. Optical limiting with C60 and other fullerenes. Appl. Opt. 1997, 36, $7794-7798$. [CrossRef] [PubMed]

63. McEwan, K.J.; Milsom, P.K.; James, D.B. Nonlinear Optical Effects in Carbon Suspension. In Proceedings of the SPIE 3472, Nonlinear Optical Liquids for Power Limiting and Imaging, San Diego, CA, USA, 12 October 1998.

(C) 2020 by the authors. Licensee MDPI, Basel, Switzerland. This article is an open access article distributed under the terms and conditions of the Creative Commons Attribution (CC BY) license (http://creativecommons.org/licenses/by/4.0/). 